Research Article

\title{
Modeling the Use of Online Knowledge Community: A Perspective of Needs-Affordances-Features
}

\author{
Zeyu Jiao $\mathbb{D}^{1},{ }^{1}$ Jianbin Chen $\mathbb{D}^{2},{ }^{2}$ and Eunjin Kim $\mathbb{D}^{1}$ \\ ${ }^{1}$ Kyonggi University, Suwon 443-760, Gyeonggi-do, Republic of Korea \\ ${ }^{2}$ Beijing Union University, Beijing 100101, China \\ Correspondence should be addressed to Jianbin Chen; jianbin.chen@buu.edu.cn
}

Received 26 October 2021; Accepted 16 November 2021; Published 27 December 2021

Academic Editor: Daqing Gong

Copyright (c) 2021 Zeyu Jiao et al. This is an open access article distributed under the Creative Commons Attribution License, which permits unrestricted use, distribution, and reproduction in any medium, provided the original work is properly cited.

With the support of network information technology, the Online Knowledge Community (OKC) has emerged. Among different OKC applications, some entered into the new era of popular knowledge production, while others experienced the process to decline. In order to solve the dilemma faced by the OKC platforms, the needs-affordances-features (NAF) perspective on OKC is proposed by taking Zhihu, one of the most popular OKC applications in China as an example. According to NAF, the psychological needs of individuals motivate the use of Zhihu to the extent to which Zhihu offers affordances that satisfy the individuals' needs. By collecting data through questionnaires and using SPSS and AMOS for data analysis, the relationship between individuals' psychological needs and Zhihu affordances is identified. This paper generates two aspects of implications. In terms of theoretical implications, a more comprehensive framework is developed for the affordances of OKC as a whole, and the NAF model is leveraged to identify related psychological needs which motivate the use of a specific OKC application-Zhihu. Further research can leverage NAF to identify different OKC platform features which satisfy the psychological needs of their targeting users to optimize the system of OKC platforms. As for practical implications, by building the relationship between the affordances of OKC platforms and users' psychological needs, marketers have to realize that although the digital platform system has a certain degree of imitability, the value positioning, user community, and core capabilities behind those platforms are all different. Thus, the platform system must also be differentiated. In order to determine the appropriate business model, a clear understanding of these organizational features should be identified.

\section{Introduction}

Knowledge management has attracted the attention of many researchers due to its close relationship with organizational performance [1]. In the Internet age, the "Online Knowledge Community" (OKC) that integrates the functions of "knowledge sharing" and "online social networking" has emerged. With the opening of registration restrictions, a large number of ordinary users have poured in. Representative OKC platforms such as Douban and Zhihu have entered the second stage of development from the early stage of highly acclaimed and rapid development: the era of popular knowledge production [2]. The vast information capacity and random insertion and editing at any time have significantly increased the amount of information and the level of confusion, which changed the traditional online communication methods [3]. At the same time, the operation of knowledge communities is facing a complex situation. For example, although Wukong Questions and Answers (Q\&A) application persuaded over about 300 influencers of Zhihu to join with a high salary in 2017, the server of Wukong Q\&A ceased operation in 2021 [4]. During the same period, Zhihu ushered in its tenth birthday celebration, and there were rumors of listing on the stock market. There is the success of Zhihu, while there is also the shutdown of Encarta, the failure of Google Answers, the decline of Wikipedia $[5,6]$, and the quit of Wukong Q\&A, which operated less than four years independently.

Of these OKC platforms, why do high-quality creators prefer Zhihu? From a social-technical perspective, the OKC 
platform is a collection of users' behavioral possibilities and needs in social media and organizational environments [7]. Its value is created by digital technology and is cocreated by the interaction between the user, the technology, and the purpose of use [8]. Ongus [9] also mentioned that the quality and relevance of technology resources and information content are closely related to users' needs. Therefore, the platform functions or resources enabled by platform features are essential for users' needs. However, the current literature has not yet studied this mechanism, resulting in a "black box" of the platform system. In the research of Facebook using motivations, the needs-affordances-features (NAF) model was first suggested by focusing on platform characteristics in the context of social media [10]. According to NAF, the psychological needs of individuals motivate the use of applications to the extent to which these applications offer affordances that satisfy individuals' needs (ibid). As OKC is similar to social media given the "online social networking" functions, the NAF model is proposed to address the following questions:

(1) What innate psychological needs do people seek to satisfy through OKC?

(2) What are the main affordances provided by OKC?

(3) Which of these OKC affordances meet which psychological needs?

In this paper, according to the literature review, the needs-affordances-features (NAF) model is used to identify the relationship between psychological needs, affordances, and features. Based on the research of psychological needs, OKC affordances, and Zhihu features, hypotheses of this paper are suggested, and the conceptual framework is sorted out. In the final, from data collection and analysis, the relationship between individuals' psychological needs and Zhihu affordances is identified. The result shows that each of the Zhihu affordances is likely related to fulfilling some psychological needs. For example, the need for autonomy can motivate people to use Zhihu that has the affordance of browsing others' content, while the need for relatedness can motivate the use of Zhihu that has affordances of selfpresentation, relationship formation, and meta-voicing.

In terms of the research gap, although current research has noticed that the platform's community ecology and value cocreation may play an essential role in optimizing the platform, the platform is mainly regarded as an intermediary connection point and ecological core node $[11,12]$. That is to say, there is a lack of analysis of the internal micromechanism based on the platform's individualization and differentiation. Therefore, this paper will address the "black box" of the platform system. With the consideration of platform affordances, the interaction relationship between the platform and users will be studied from the dimensions of core functions and resources to enrich the theoretical system of the platform further and achieve theoretical innovation. In the view of practice, from the fact that Wukong Q\&A has invested billions in the construction of the community, although it still fell to the ground, it can be seen that different platform affordances could create different community ecology. The research of this topic can guide more platforms to design more effective OKC applications under the premise of unifying user needs and organizational characteristics, which could lead to avoiding waste of social resources and improving the success rate of Internet innovation.

\section{Literature Review}

2.1. Online Knowledge Community (OKC). Online Knowledge Community (OKC) refers to a virtual space where users scattered in different regions carry out knowledge exchange and interpersonal interaction with the support of network information technology [13], which is a typical socialtechnical system [14]. OKC has the collaborative ordering of the social and knowledge systems, and users are the driving force of ordering the two systems $[3,15]$.

Currently, OKC research focuses on three hot areas: user research, content research, and community research [2]. User research mainly explores OKC users' behavior characteristics and patterns and analyzes user motivation for participation and the interaction between users. Content research focuses on content quality measurement and evaluation, semantic analysis, and topic recognition, influencing factor analysis, relationship research, and so forth. Community research is about conducting research on community operation mechanisms, content generation models, and community comparisons. The representative viewpoints are as follows: the field of information management emphasizes the impact of IT technology on knowledge proliferation [16]; the field of sociology pays more attention to the impact of trust on online interaction [17]. Guan et al. [18] believed that knowledge inflow is the key and examine the antecedents of knowledge contribution behavior in multiple dimensions. In contrast, Lai et al. [19] and Zhao and Huang [20] believed that knowledge search is equally important. They examine the antecedents of knowledge search behavior from the perspectives of behavior attitude, subjective norms, and ability beliefs. In terms of user research, opinion leaders or leading users usually have more experience or mastered more professional knowledge, so their behaviors are more exploratory or creative, and they are easier to gain trust. In addition, knowledge contribution is their important active behavior [21].

2.2. Affordance Theory. Affordance originally refers to the support that objective things can provide for a certain behavior, that is, action possibilities permitted by properties of objects [22]. In recent years, it has become more popular in organizational research and can be used to better understand the impact of the combination of new technologies and organizational characteristics on organizational innovation and operations [23]. "Affordance" provides not only a strong theoretical perspective for studying the relationship between technology and personnel in an organization but also a better language for the structured and patterned description of specific practices [24]. 
As a commonly used communication method, social media affordances have an important influence on the organization's communication process, employee and user behavior, and psychology, so it is currently a hot topic of affordance research. Postigo [25] first analyzed, from the perspective of social-technical interaction, how YouTube guides users to conduct behaviors that are beneficial to the commercial interests of the platform through the design of platform architecture. Rice et al. [7] defined social media affordances as the relationship between the action possibility and the need (or purpose) perceived by users aggregated in social media and the organizational environment under the constraints of the potential features/functions of the social media platforms. Majchrzak and Faraj [23] studied the relationship between the different ways through which employees participate in publicly visible conversations on social media platforms and knowledge sharing. Sun et al. [26] divided the use of social media platforms into three categories: interactivity (conversations between users and comments on related information), accessibility (users can obtain relevant information), and sociality (users establish connections with other users).

There are many research results around the dimension of affordances. Treem and Leonardi [27] proposed four dimensions of social media affordances, visibility, associating, editability, and persistence, which have been commonly used [24, 26, 28]. Majchrzak and Faraj [23] proposed four dimensions of affordances for knowledge sharing (meta voicing, trigger attending, network-informed associating, generative role-taking). In addition, there are six dimensions of functional media affordances [7], ten dimensions of communication affordances [29], and six dimensions of social business technology affordances [30]. As for new media affordances, Pan and Liu [31] proposed production affordances (including editability, reviewability, replicability, scalability, and associability), social affordances (including greet-ability, emotion-ability, coordinate-ability, and connect-ability), and mobile affordances (including portability, availability, locatability, and multimediality), which reflect the initiative of the information prosumer.

The most integrated literature is proposed by Karahanna et al. [10], who divide social media affordances into egocentric and allocentric affordances based on the theory of self-determination and psychological ownership. In addition, the research framework for social media adoption and use is proposed, which is the needs-affordances-features (NAF) model, and an empirical study of affordances is conducted with Facebook as an example. Zhang and Huang [32] discussed the realization of platform affordances from aspects of technology affordances and social affordances and emphasized that users' perceptions and actions must be considered when gaining insight into the complex relationship between technology and society.

Based on the above literature, OKC affordances could be divided into platform affordances and product affordances in this research. Platform affordances include technology affordances and social affordances. However, this paper focuses on the relationship between individuals' psychological motivations and $\mathrm{OKC}$ affordances. Compared to technology affordances which provide technical support for platform affordances, social affordances can better reflect the relationship between platform affordances and people's psychological needs for using a certain OKC platform. As a result, social affordances will be used as platform affordances in this research, which is realized by platform functions, such as Zhihu platform features. Product affordances focus on the affordances of OKC knowledge resources, referred to as knowledge affordances (see Table 1).

2.3. NAF Perspective for OKC. The psychology literature shows that people are driven to engage in activities that fulfill their innate psychological needs. Therefore these psychological needs are stimulating states that act as motivations for action [33]. Based on this premise, a needs-affordancesfeatures (NAF) perspective shows that innate psychological needs motivate people to use OKC apps, which have affordances to satisfy their psychological needs potentially. For example, OKC apps provide the affordance to connect with others, through features such as "Following" and "Chatting" on Zhihu. This affordance can be used to satisfy people's psychological needs for relatedness. Therefore, this psychological need drives them to participate in using Zhihu features that provide this affordance to meet this psychological need (see Figure 1).

2.4. Relationship between Psychological Needs and OKC Affordances. Although there is no research to categorize psychological needs in the OKC context, research on human motivations shows that "motivation can be conceived as a duality" [34]. On the one hand, people focus on the self. On the other hand, they strive for relationships between the self and others. Hermans [35] suggested the former motivation as the S-motive and the latter as the O-motive. Based on self-determination theory (SDT) $[33,36]$ and psychological ownership theory (POT) [37-39], seven psychological needs are listed, which span the two polarities and illustrate people's self-focused and other-focused motivations. Thus, these two theories are synthesized in this paper to show psychological needs in a more comprehensive way. According to the terminology of Hermans [35], these seven psychological needs are divided into the self-focused group, also called S-needs (need for autonomy, competence, having a place, coming to know the self, maintaining continuity of self-identity, and one aspect of expressing self-identity), and the other-focused group, also called O-needs (need for relatedness and one aspect of expressing self-identity).

According to Karahanna et al. [10], there are 12 social media affordances, which constitute egocentric affordances (self-presentation, content sharing, and interactivity) and allocentric affordances (presence signaling, relationship formation, group management, browsing other's content, meta-voicing, communication, collaboration, competition, and sourcing). As OKC is a typical social-technical system equipped with the function of "online social networking," these 12 social media affordances will be used to analyze the OKC social affordances. However, in addition to social 
TABLE 1: OKC affordances concept system.

\begin{tabular}{llrr}
\hline & Affordance concept system & Platform factors \\
\hline \multirow{2}{*}{ OKC affordances } & Platform affordances & Social affordances & Platform functions \\
& Product affordances & Knowledge affordances & Platform resources \\
\hline
\end{tabular}

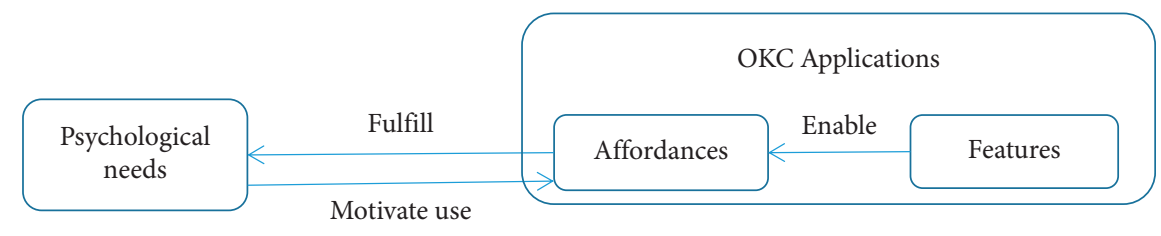

Figure 1: Logic of the NAF perspective.

affordances, OKC has its specific product, which is knowledge. According to Shi et al. [40], knowledge affordances are defined as unique attributes of knowledge that meet the needs of consumers, which can be measured in 4 dimensions (reliability, economies, selectivity, and uniqueness). In order to map the OKC affordances to psychological needs, Table 2 is shown based on former research [10] and six OKC researchers (see Table 3 for details of term definitions).

2.5. Literature Gaps. First, there is a lack of platform features in the context of OKC research. At present, the OKC research has three hot areas: users, content, and communities/ platforms, and OKC affordances have also attracted much attention. However, the OKC research focuses on the field of subrole characteristics and its socialization mechanism and lacks attention to platform differences. Second, people's attention to the role of psychological needs in motivating the use of the OKC platforms is limited. In particular, there has not been a comprehensive theoretical-based attempt to determine a set of psychological needs that are salient in the OKC environment. In most studies, the focus is not on theorizing around psychological needs, but the needs variable is one of the many variables included in the research model. Third, current studies did not adopt a systematic method to identify the OKC affordances that meet these needs. On the contrary, most people measure need satisfaction to confirm whether affordances meet people's psychological needs. The focus on the relationship between psychological needs and OKC affordances provides valuable operational design guidelines for information system researchers and practitioners. Our research aims to address these gaps.

\section{Research Model and Hypotheses}

There are three steps of developing the NAF model in the use of the Zhihu application. Firstly, to understand what psychological motivations of using this app, the affordances provided by the Zhihu platform should be identified. In 2011, the mission of Zhihu was officially launched, which is "allowing people to share knowledge, experience and insights better and find their own answers" [58]. After nearly ten years of development, Zhihu announced the brand renewal and upgrade at the 2021 New Knowledge Youth Conference. The brand slogan has been upgraded from "If there is a question, go to Zhihu" to "If there is a question, there will be an answer" (ibid). These show that self-presentation, content sharing, browsing others' content, and sourcing are salient affordances of Zhihu. Based on the functions of chatting and live Q\&A, liking or collecting others' content, and voting for what others posted, it is obvious that communication and meta-voicing are also affordances of Zhihu. In addition, there is a function of "Quanzi" in Zhihu, which offers a community for the group of people who have common interests, where they could share and communicate about their experience and opinions in their own circle. As a result, relationship formation is also one of the social affordances of Zhihu. After identifying salient affordances, the most popular features of Zhihu were selected from a synthesis of research on the condition that affordances are provided by specific features of an object $[52,57,59,60]$. With the combination of its knowledge properties, six researchers with research expertise in OKC (three faculty and three doctoral students) are asked to map the features to the $13 \mathrm{OKC}$ affordances listed in Table 2. Table 4 illustrates the result of the mapping of Zhihu features to Zhihu affordances. Therefore, Zhihu affordances are identified as self-presentation, content sharing, relationship formation, browsing others' content, meta-voicing, communication, sourcing, and knowledge attributes.

In order to predict which Zhihu affordances meet which psychological needs, the hypotheses are suggested as follows.

According to Deci [61], autonomy is defined as people's innate psychological needs to act authentically in their own life. Everyone is inherently eager for autonomy [62]. They participate in activities, not because of social norms or pressures but because they are free to choose $[33,63]$. Therefore, we suggest that self-presentation, content sharing, relationship formation, browsing others' content, and sourcing are affordances that motivate users to use Zhihu. For example, those affordances allow individuals of Zhihu to choose how to present themselves (through uploading video and photos, disclosing locations), what content to share, whom to follow, what kind of community to join, and what questions to suggest or answer, which leads to hypothesis 1 . 
TABLE 2: Mapping of the psychological needs to OKC affordances.

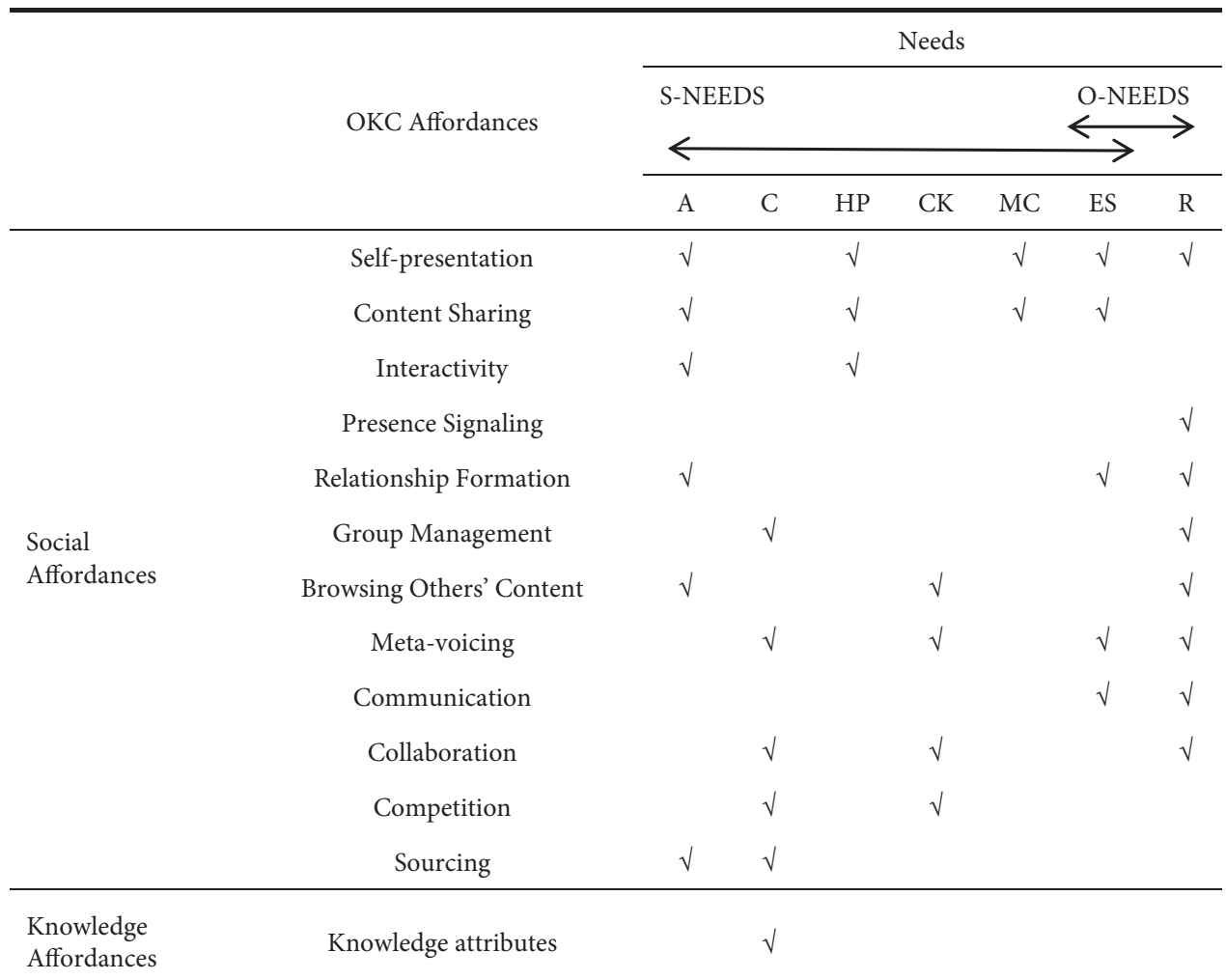

Note: $\mathrm{A}=$ autonomy; $\mathrm{C}=$ competence; $\mathrm{HP}=$ having a place; $\mathrm{CK}=$ coming to know the self; $\mathrm{MC}=$ maintaining continuity of self-identity; $\mathrm{ES}=$ expressing selfidentity; $\mathrm{R}=$ relatedness.

H1: The need for autonomy can motivate the use of Zhihu that has these affordances: self-presentation, content sharing, relationship formation, browsing others' content, and sourcing.

In 1991, Deci and Ryan illustrated that relatedness is individuals' innate psychological need to be connected to others. In 2000, Deci and Ryan extended the definition as the need "to love and care and to be loved and cared for." Thus, we posit that a set of Zhihu affordances-self-presentation, relationship formation, browsing others' content, meta-voicing, and communication-can help people satisfy the need for relatedness by creating social connections with others. This can be realized by reaching a lot of users, joining an online group, knowing what others are doing, reacting to others' posts, and so forth $[64,65]$. For example, in the context of Zhihu, users can increase social interactions by posting personal information (self-presentation), following a user (relationship formation), browsing others' posts (browsing others' content), voting for a post (metavoicing), sending an instant message to others (communication), and so forth. Therefore, the $\mathrm{H} 2$ is proposed as follows.

$\mathrm{H} 2$ : The need for relatedness can motivate the use of Zhihu that has these affordances: self-presentation, relationship formation, browsing others' content, meta-voicing, and communication.

Bauer and McAdams [66] analyzed that competence refers to people's innate psychological needs to deal with their environment effectively. It is the psychological needs that can be achieved by having an impact on individuals or the environment. White [67] showed that individuals need to feel competent in controlling or altering the environment and finding opportunities to increase their own knowledge or skills. Therefore, people who have a high demand for competence are more likely to seek affordances that provide them with opportunities to apply or expand their knowledge in the environment. Thus, we suggest that the affordances of meta-voicing, sourcing, and knowledge attributes can fulfill individuals' needs for competence by providing feedback to others' posts, responding to others' questions, searching answers, subscribing to valuable content, attending online courses, and so on. Thus, hypothesis 3 is suggested.

H3: The need for competence can motivate the use of Zhihu that has the following affordances: meta-voicing, sourcing, and knowledge attributes.

In terms of having a place, it refers to people's innate psychological needs to possess a place where they can create their own space $[68,69]$. Pierce et al. [70] suggest 
TABLE 3: OKC affordances.

\begin{tabular}{|c|c|c|}
\hline Affordances & Definitions & Example features \\
\hline Self-presentation & $\begin{array}{l}\text { Social affordances } \\
\text { Users can display and present information related to } \\
\text { themselves. This includes sharing information that } \\
\text { somehow portrays users and shows who they are, their } \\
\text { values and preferences, their expertise, etc. Updating } \\
\text { descriptive information about themselves, such as } \\
\text { gender, occupation, and location; and posting content } \\
\text { involving pictures and videos related to themselves } \\
\text { [41-44] }\end{array}$ & $\begin{array}{l}\text { Posting my own content on Zhihu; sharing my own video } \\
\text { on YouTube; updating my profile on Zhihu; writing } \\
\text { personal opinions on Zhihu }\end{array}$ \\
\hline Content sharing & $\begin{array}{l}\text { Users can share and distribute content unrelated to them } \\
\text { to others (e.g., sharing posts, video) }[27,45,46]\end{array}$ & $\begin{array}{c}\text { Sharing links of other people's articles on Zhihu; sharing } \\
\text { others' videos and photos on Instagram }\end{array}$ \\
\hline Interactivity & $\begin{array}{l}\text { Users can walk around in real time and change their } \\
\text { virtual environment (e.g., to build in-world artifacts) [41] }\end{array}$ & Moving around in World of Warcraft \\
\hline Presence signaling & $\begin{array}{c}\text { Users can indicate their existence and know whether } \\
\text { other users are accessible }[43,44,47]\end{array}$ & "Who is online" on Instagram \\
\hline $\begin{array}{l}\text { Relationship } \\
\text { formation }\end{array}$ & $\begin{array}{l}\text { Users can establish relationships with others, including } \\
\text { joining groups or online communities }[27,45]\end{array}$ & $\begin{array}{l}\text { Following other users on Zhihu; joining an online } \\
\text { community (e.g., "Quanzi" on Zhihu) }\end{array}$ \\
\hline $\begin{array}{l}\text { Group } \\
\text { management }\end{array}$ & $\begin{array}{l}\text { Users can form groups and online communities and } \\
\text { manage them. The focus is on the management or } \\
\text { administration of groups }[45,46]\end{array}$ & $\begin{array}{l}\text { Illegal content management on Zhihu, forming a } \\
\text { "Quanzi" on Zhihu }\end{array}$ \\
\hline $\begin{array}{l}\text { Browsing Other's } \\
\text { content }\end{array}$ & $\begin{array}{l}\text { Users can view others' content and receive alerts to pay } \\
\text { attention to others' content }[41,42,45]\end{array}$ & $\begin{array}{l}\text { Browsing others' content on Zhihu, receiving } \\
\text { notifications on LinkedIn }\end{array}$ \\
\hline Meta-voicing & $\begin{array}{l}\text { Users can participate in online conversations by } \\
\text { responding to other people's status, profile, content, and } \\
\text { activities online and viewing other people's responses to } \\
\text { their status, profile, content, and activities. In meta-voice, } \\
\text { the user "not only has to express his or her opinion, but } \\
\text { also add meta-knowledge to content already online." } \\
{[23,48]}\end{array}$ & $\begin{array}{l}\text { Voting on a post on Zhihu, answering questions on } \\
\text { Zhihu, liking what others post on Zhihu }\end{array}$ \\
\hline Communication & $\begin{array}{l}\text { Users can chat or send messages with others directly } \\
\qquad[41,44,47]\end{array}$ & $\begin{array}{l}\text { Chatting on Zhihu, communicating with others on } \\
\text { Google+ }\end{array}$ \\
\hline Collaboration & $\begin{array}{l}\text { Users can collaborate with others, such as collaborating } \\
\text { with others to create content on Wikipedia }[23,43,48]\end{array}$ & Adding, deleting, and editing content on Zhihu \\
\hline Competition & $\begin{array}{l}\text { Users are able to compete with others, which includes } \\
\text { competing in online games [10] }\end{array}$ & Completing tasks in World of Warcraft \\
\hline Sourcing & $\begin{array}{l}\text { Users are able to ask for resources or funds, including } \\
\text { meeting others' requests for funds or resources [10] }\end{array}$ & Asking or answering questions on Zhihu \\
\hline
\end{tabular}

Knowledge affordances

Reliability: It refers to the extent to which the answers on social Q\&A websites make users feel trustworthy and reliable [49]. Users think that the answer is of high quality only when they believe that the source and content of the answer are reliable [50]

Selectivity: Users can subscribe to specific content or sources of information [51]

Economies: It means that the subject obtains relatively maximum benefits with relatively minimum investment to obtain benefits most economically and meet the needs

Knowledge
attributes of survival and development [53]

Uniqueness: It is defined as individuals pursuing unique characteristics different from others by acquiring, using, and disposing of consumer goods [55]. Novelty is a concept closely related to uniqueness. Novelty refers to the extent to which the answers on social Q\&A websites make users feel innovative. Innovative answers will bring new ideas to users and will also be regarded as highquality answers by users $[49,56]$
The reliability of Zhihu content is reflected in its questions, answers, articles, videos, pictures, etc.

Zhihu involves popular and unpopular content in multiple sections, and the content knowledge within each section is highly subdivided [52]

Zhihu provides users with a free Q\&A community [54]. Users can spend less money to ask questions to experts in related fields

In-depth content production is different from the knowledge provided by other Q\&A platforms. Online and offline knowledge products are carried out at the same time [57] 
TABLE 4: Mapping of Zhihu features to Zhihu affordances.

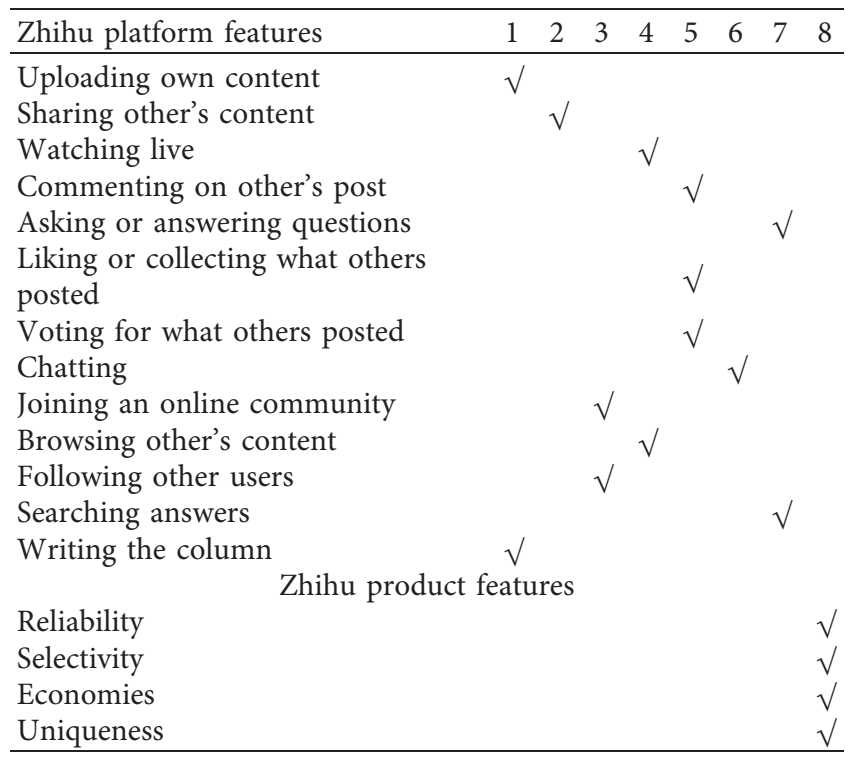

1-7: self-presentation, content sharing, relationship formation, browsing others' content, meta-voicing, communication, sourcing, and knowledge attributes.

that a sense of having a place can be partly realized by the personalization of individuals' surroundings. Applying this definition to cyberspace, users can fulfill their needs for having a place by investing time, energy, or emotion in creating their own virtual world through self-presentation (such as posting personal photos or videos on Zhihu) and content sharing (such as sharing others' content on Zhihu). In this way, a sense of having a place can be created by engaging in personalizing the cyberspace. As a result, hypothesis 4 can be proposed.

H4: The need for having a place can motivate the use of Zhihu that has these affordances: self-presentation and content sharing.

As for coming to know the self, Pierce et al. [71] illustrated it as individuals' innate psychological needs to identify who they are and learn about themselves. Selfidentity can be developed through self-awareness, such as comparing themselves with others when people interact with their surroundings [72]. In addition, the sense of coming to know the self can be achieved by receiving feedback from others and seeing how other people think of themselves [73]. Thus, people can reflect their feelings, thoughts, and behaviors, which enable them to discover what kind of people they are. Therefore, the psychological needs for coming to know the self can be fulfilled by these affordances: browsing others' content (which helps individuals compare themselves to others) and meta-voicing (which enables individuals to see reflected appraisal). Therefore, hypothesis 5 is suggested.

$\mathrm{H} 5$ : The need for coming to know the self can motivate the use of Zhihu that has these affordances: browsing others' content and meta-voicing.
Expressing self-identity is defined as people's innate psychological needs to communicate their identities with others [71]. For example, Zhihu users can satisfy their needs for expressing self-identity by self-presentation (through disclosing their personal information such as profile photos and education), content sharing (through sharing articles), relationship formation (through following other Zhihu users or joining online communities), meta-voicing (through commenting on or voting for others' posts), and communication (through chatting directly with other Zhihu users). Therefore, hypothesis 6 can be proposed.

H6: The need for expressing self-identity can motivate the use of Zhihu that has these affordances: self-presentation, content sharing, relationship formation, meta-voicing, and communication.

The final psychological needs suggested in this paper are maintaining continuity of self-identity, which shows individuals' innate psychological needs to maintain emotional connections between past and present [71]. Taking Zhihu as an example, self-presenting and content sharing enable users to see who they were and who they are by the questions they asked or answered, articles they shared, photos and videos they posted, and so forth. All the content constitutes one's self-identity. Thus, we posit hypothesis 7 .

H7: The need for maintaining continuity of self-identity can motivate the use of Zhihu that has these affordances: self-presentation and content sharing.

Based on the above hypotheses, the conceptual framework can be shown in Figure 2.

\section{Research Methods}

4.1. Questionnaire Design. Based on previous research of psychological needs and Zhihu features, questionnaire 1 and questionnaire 2 are designed to test the model of this paper. In order to measure seven variables of psychological needs, 20 question items are suggested. A adopts three-question items from Deci [61] and Deci and Ryan [33, 62, 63]. $\mathrm{R}$ is measured by the scale of the research from Deci and Ryan $[63,74]$, Jenkins-Guarnieri et al. [64], and Seder \& Oishi [65]. C adopts the scale from Bauer and McAdams [66] and White [67]. HP adopts two-question items from Barki et al. [68], Harrison and Barthel [69], and Pierce et al. [70]. CK is measured by the scale of Pierce et al. [71], Festinger [72], and Mead [73] while ES and MC adopt the source from Pierce et al. [71] to be the measurement scale (see in questionnaire 1). In questionnaire 2, 17 question items are suggested to measure the extent to which the use of or feeling Zhihu features. In this study, every measurement item is measured using the five-point Likert scale. 1 for "strongly disagree," 2 for "disagree," 3 for "undecided," 4 for "agree," and 5 for "strongly agree." 
TABLE 5: Scale items.

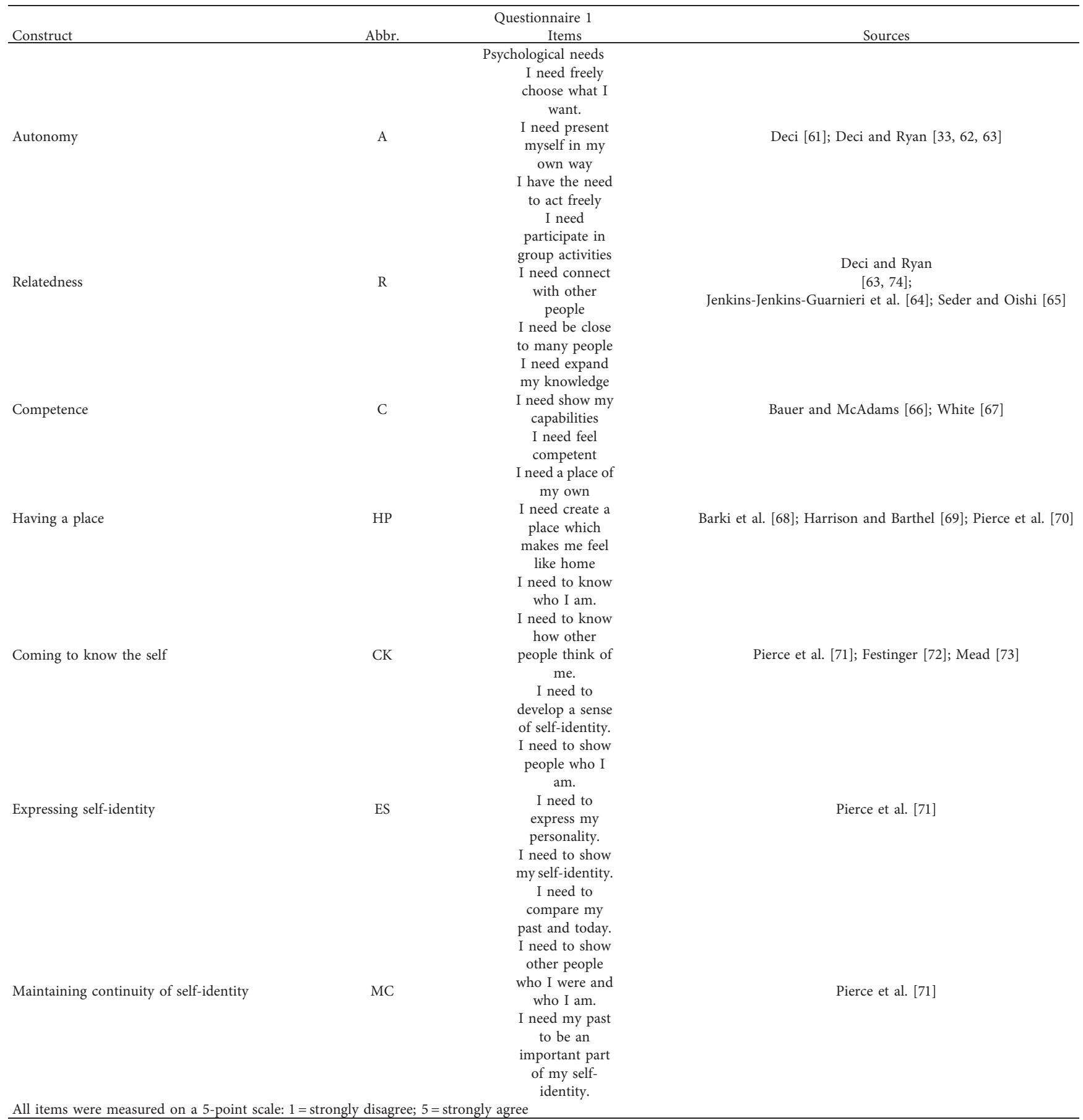


TABle 5: Continued.

\section{Questionnaire 2}

\begin{tabular}{|c|c|c|}
\hline \multirow{14}{*}{$\begin{array}{l}\text { Frequency of using Zhihu platform features (aggregate } \\
\text { of use across features) }\end{array}$} & \multicolumn{2}{|c|}{$\begin{array}{l}\text { The extent to which the use of or feeling the following Zhihu features (all items were measured on a } 5 \text {-point } \\
\text { scale Zhihu platform features: } 1=\text { never, } 5=\text { very often Zhihu product features: } 1=\text { strongly disagree, } \\
5=\text { strongly agree) }\end{array}$} \\
\hline & F1 & Uploading own content \\
\hline & $\mathrm{F} 2$ & Sharing other's content \\
\hline & F3 & Watching live \\
\hline & $\mathrm{F} 4$ & Commenting on other's post \\
\hline & F5 & Asking or answering questions \\
\hline & F6 & Liking or collecting what others posted \\
\hline & F7 & Voting for what others posted \\
\hline & F8 & Chatting \\
\hline & F9 & Joining an online community \\
\hline & F10 & Browsing other's content \\
\hline & F11 & Following other users \\
\hline & F12 & Searching answers \\
\hline & F13 & Writing the column \\
\hline \multirow{4}{*}{ Degree of feeling Zhihu product features } & F14 & Reliability \\
\hline & F15 & Selectivity \\
\hline & F16 & Economies \\
\hline & F17 & Uniqueness \\
\hline
\end{tabular}

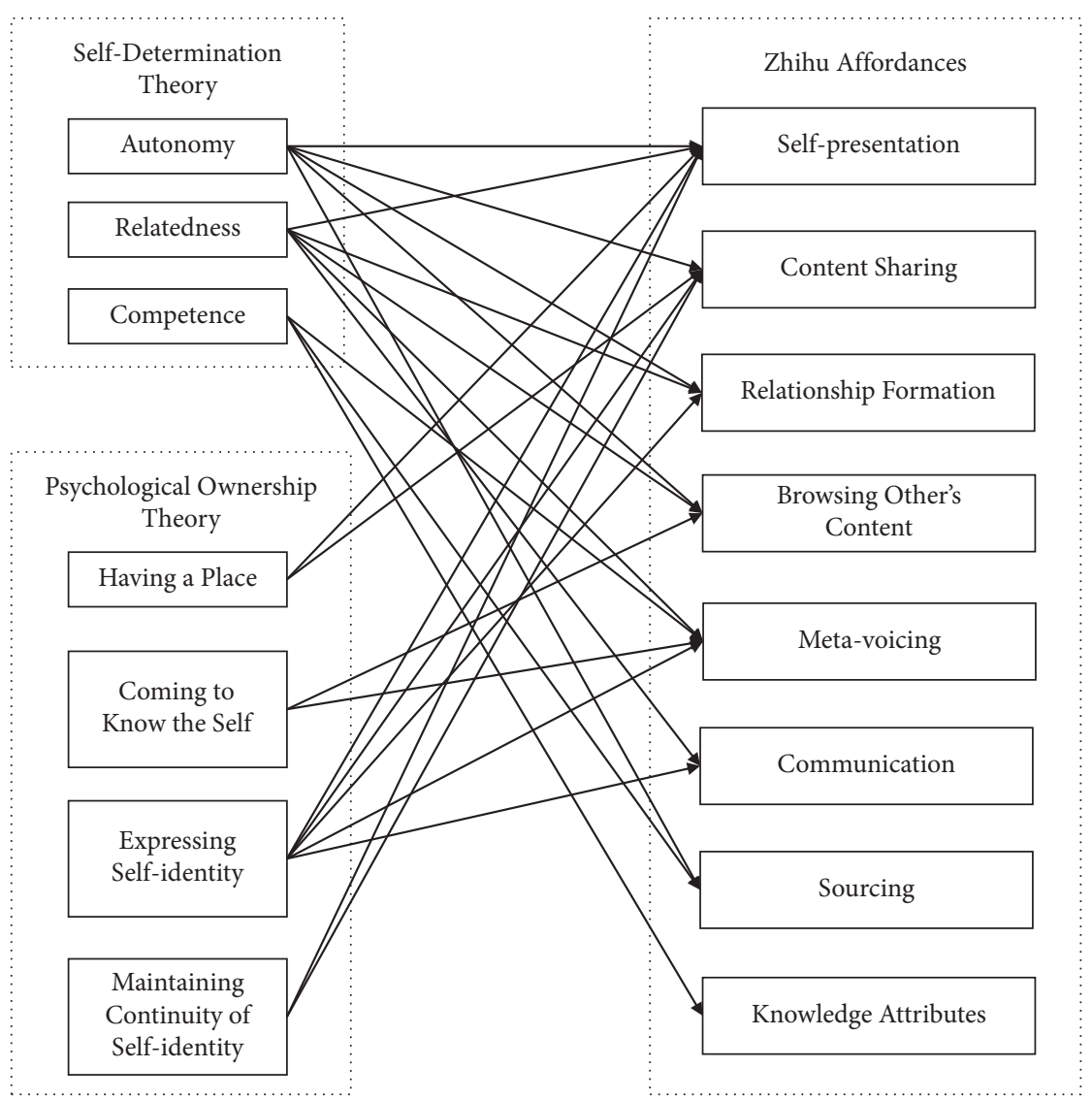

FIGURE 2: NAF model for Zhihu affordances use.

4.2. Data Collection. Taking into account the time constraints and sample size, the research scope is mainly selected in the first-tier cities in China that have a large number of people using Zhihu. First, the questionnaire was distributed and collected in a small range through the social network of teachers and classmates to conduct a preliminary test of the questionnaire. After the questionnaire was revised, a professional survey company was commissioned to invite Zhihu users in China's first-tier cities to respond online. The survey period was from June 2021 to July 2021. A total of 300 questionnaires were returned. After excluding uncompleted and regular answers, 300 questionnaires were 
finally returned, with 208 valid questionnaires, and the effective response rate was $69.3 \%$. Based on the final sample, this paper mainly adopts SPSS26.0 and Amos24.0 software to analyze the sample data as shown in Table 5 .

\section{Results and Analysis}

In this study, SPSS26.0 software and Amos24.0 software are used to analyze the research samples. Among them, the analysis methods involved in SPSS26.0 include reliability test and regression analysis, while Amos24.0 is used for confirmatory factor analysis.

5.1. Reliability and Validity Test. Reliability refers to the consistency or stability of the measurement results obtained by measurement tools [75]. In this paper, Cronbach's Alpha reliability test is used for testing variables. In terms of validity, it refers to the degree to which measurement tools can accurately measure the things that need to be measured [76]. This paper uses confirmatory factor analysis to test the validity of variables, which is mainly used to verify convergent validity and discriminant validity. According to Hair [76], the absolute value of factor loading should be at least 0.5 or more, and the best index value should be more than 0.7 . In addition, the average variance extraction (AVE) index value should be more than 0.5 . The value of the construct reliability should be higher than 0.7 to judge whether it has convergent validity. Fornell and Larcker [77] pointed out that the existence of discriminant validity should be judged based on whether the square root of AVE is higher than the correlation coefficient value between the two-factor constructs. This study uses the maximum likelihood method to estimate the model, and $\chi^{2} / \mathrm{df}$, RMSEA, SRMR, NFI, CFI, TLI, IFI indicators are used to verify the model fitting degree in this paper.

It can be seen from Table 6 that the reliability of $\mathrm{A}, R, \mathrm{C}$, $\mathrm{HP}, \mathrm{CK}, \mathrm{ES}$, and $\mathrm{MC}$ is $0.886,0.748,0.843,0.767,0.855$, 0.801 , and 0.832 , respectively, indicating that the questionnaire has good reliability. In addition, as the result shows that $\chi^{2} / \mathrm{df}=1.330, \mathrm{RMSEA}=0.040, \mathrm{SRMR}=0.043$, $\mathrm{NFI}=0.905, \mathrm{CFI}=0.974$, TLI $=0.967, \mathrm{IFI}=0.975$, it indicates that the confirmatory factor analysis model fits well. The composite reliability values of A, R, C, HP, CK, ES, and $\mathrm{MC}$ are $0.887,0.752,0.843,0.767,0.857,0.808$, and 0.835 , which are all above 0.7 , and the AVE values are 0.723 , $0.503,0.644,0.666,0.584$, and 0.629 , respectively, which are above 0.5 , so it shows that the questionnaire has good convergent validity.

Table 7 shows the mean and standard deviation of $\mathrm{A}, \mathrm{R}$, C, HP, CK, ES, and MC. The AVE values of A, R, C, HP, CK, ES, and MC are 0.850, 0.709, 0.802, 0.789, 0.816, 0.764, and 0.793 , respectively, which are higher than their corresponding correlation coefficients, which shows that the questionnaire has good discriminant validity.

5.2. Regression Analysis. Regression analysis is a statistical analysis method to determine the interdependent relationship between two variables or multiple variables. Therefore, this paper chooses regression analysis to test the hypothesis, in which gender, age, and Internet experience (in years) are used as control variables.

Table 8 shows the predictive effect of the predictor variables on the dependent variables and the magnitude of the explanation rate. Thus, the results are shown below.

Taking self-presentation as the dependent variable, it can be seen that relatedness, having a place, and expressing selfidentity have a significant positive predictive effect on selfpresentation $(\beta=0.223, \quad p<0.01 ; \quad \beta=0.300, \quad p<0.001$; $\beta=0.219, p<0.01$, respectively). In addition, the explanatory rate of the predictor variables to self-presentation is $29.4 \%$.

Taking content sharing as the dependent variable, it is shown that having a place and expressing self-identity have a significant positive predictive effect on content sharing ( $\beta=0.260, p<0.001 ; \beta=0.179, p<0.05$, respectively). The explanatory rate of the predictor variables to content sharing is $15.1 \%$.

Taking relationship formation as the dependent variable, it can be seen that relatedness and expressing self-identity have a significant positive predictive effect on relationship formation $(\beta=0.245, p<0.01 ; \beta=0.340, p<0.001$, respectively). The explanatory rate of the predictor variable to relationship formation is $25.2 \%$.

Taking browsing others' content as the dependent variable, it is shown that autonomy and coming to know the self have a significant positive predictive effect on browsing others' content $(\beta=0.309, p<0.001 ; \beta=0.246, p<0.01$, respectively). The explanatory rate of the predictor variable to browsing others' content is $16.9 \%$.

Taking meta-voicing as the dependent variable, it can be seen that relatedness, competence, coming to know the self, and expressing self-identity have a significant positive predictive effect on meta-voicing $(\beta=0.227, p<0.01$; $\beta=0.270, p<0.001 ; \beta=0.189, p<0.01 ; \beta=0.167, p<0.05$, respectively). The explanatory rate of predictor variables for meta-voicing is $39.7 \%$.

Taking communication as the dependent variable, it can be seen that the predictive effects of the various variables of psychological needs are not significant.

Taking sourcing as the dependent variable, it can be seen that competence has a significant positive predictive effect on sourcing $(\beta=0.366, p<0.001)$, and the explanatory rate of the predictor variable to sourcing is $14.9 \%$.

Taking knowledge attributes as the dependent variable, it can be shown that competence has a significant positive predictive effect on knowledge attributes $(\beta=0.369$, $p<0.001$ ), and the explanatory rate of the predictor variable to knowledge attributes is $14.4 \%$.

\section{Discussion}

From the data results above, the following observations could be reached. One is that each of the Zhihu affordances is likely to be related to fulfilling some psychological needs. At the same time, the salient psychological needs that drive people to use Zhihu could be identified. The other is that links between individuals' psychological 
TABLE 6: Reliability and convergent validity.

\begin{tabular}{|c|c|c|c|c|c|}
\hline Constructs & Items & Loadings & Cronbach's alpha & Composite reliability & Average variance extracted \\
\hline \multirow{3}{*}{ A } & A1 & 0.835 & \multirow{3}{*}{0.886} & \multirow{3}{*}{0.887} & \multirow{3}{*}{0.723} \\
\hline & $\mathrm{A} 2$ & 0.859 & & & \\
\hline & A3 & 0.856 & & & \\
\hline \multirow{3}{*}{$\mathrm{R}$} & $\mathrm{R} 1$ & 0.738 & \multirow{3}{*}{0.748} & \multirow{3}{*}{0.752} & \multirow{3}{*}{0.503} \\
\hline & $\mathrm{R} 2$ & 0.698 & & & \\
\hline & R3 & 0.691 & & & \\
\hline \multirow{3}{*}{$\mathrm{C}$} & $\mathrm{C} 1$ & 0.740 & \multirow{3}{*}{0.843} & \multirow{3}{*}{0.843} & \multirow{3}{*}{0.644} \\
\hline & $\mathrm{C} 2$ & 0.888 & & & \\
\hline & $\mathrm{C} 3$ & 0.771 & & & \\
\hline \multirow{2}{*}{ HP } & HP1 & 0.801 & \multirow{2}{*}{0.767} & \multirow{2}{*}{0.767} & \multirow{2}{*}{0.623} \\
\hline & HP2 & 0.777 & & & \\
\hline \multirow{3}{*}{ CK } & CK1 & 0.779 & \multirow{3}{*}{0.855} & \multirow{3}{*}{0.857} & \multirow{3}{*}{0.666} \\
\hline & $\mathrm{CK} 2$ & 0.799 & & & \\
\hline & CK3 & 0.868 & & & \\
\hline \multirow{3}{*}{ ES } & ES1 & 0.724 & \multirow{3}{*}{0.801} & \multirow{3}{*}{0.808} & \multirow{3}{*}{0.584} \\
\hline & ES2 & 0.790 & & & \\
\hline & ES3 & 0.778 & & & \\
\hline \multirow{3}{*}{ MC } & $\mathrm{MC1}$ & 0.835 & \multirow{3}{*}{0.832} & \multirow{3}{*}{0.835} & \multirow{3}{*}{0.629} \\
\hline & $\mathrm{MC} 2$ & 0.780 & & & \\
\hline & MC3 & 0.762 & & & \\
\hline
\end{tabular}

Note: $\mathrm{A}=$ autonomy; $\mathrm{C}=$ competence; $\mathrm{HP}=$ having a place; $\mathrm{CK}=$ coming to know the self; $\mathrm{MC}=$ maintaining continuity of self-identity; $\mathrm{ES}=$ expressing selfidentity; $\mathrm{R}=$ relatedness.

TABLE 7: Summary statistics and discriminant validity.

\begin{tabular}{|c|c|c|c|c|c|c|c|}
\hline & A & $\mathrm{R}$ & $\mathrm{C}$ & $\mathrm{HP}$ & CK & ES & MC \\
\hline A & 0.850 & & & & & & \\
\hline $\mathrm{R}$ & $0.284^{* *}$ & 0.709 & & & & & \\
\hline $\mathrm{C}$ & $0.325^{* * *}$ & $0.560^{* * *}$ & 0.802 & & & & \\
\hline HP & $0.351^{* * *}$ & $0.266^{* *}$ & $0.311^{* * *}$ & 0.789 & & & \\
\hline CK & $0.282^{* * *}$ & $0.495^{* * *}$ & $0.277^{* *}$ & $0.393^{* * *}$ & 0.816 & & \\
\hline ES & $0.262^{* *}$ & $0.559^{* * *}$ & $0.483^{* * *}$ & $0.268^{* *}$ & $0.459^{* * *}$ & 0.764 & \\
\hline $\mathrm{MC}$ & $0.256^{* *}$ & $0.684^{* * *}$ & $0.391^{* * *}$ & $0.306^{* *}$ & $0.654^{* * *}$ & $0.446^{* * *}$ & 0.793 \\
\hline Mean & 4.437 & 3.871 & 4.299 & 4.403 & 3.921 & 3.803 & 3.858 \\
\hline S.D. & 0.726 & 0.734 & 0.697 & 0.700 & 0.791 & 0.822 & 0.842 \\
\hline
\end{tabular}

Note: ${ }^{*} p<0.05,{ }^{* *} p<0.01$, and ${ }^{* * *} p<0.001$; the diagonal elements represent the square root of the AVE.

needs and Zhihu affordances could be identified. Details are as follows.

The need for autonomy can motivate people to use Zhihu that has the affordance of browsing others' content. However, it has no relationship with self-presentation, content sharing, relationship formation, and sourcing. This means that although Zhihu users do have the freedom to determine what content to browse and when, there are some restrictions that limit users' freedom to show themselves, share content, and establish relationships. In the discussion area of the Zhihu platform, we can see many people complaining about the privacy problems of Zhihu. Some people think that it is strongly required that Zhihu set a function that can determine whether users are willing to disclose their dynamics, including the behavior of liking, collecting, and following. Otherwise, when users' friends or other people who follow the users click into the accounts, they can easily know what the users are doing or thinking in recent time. Mainly when subscribing to sensitive and private topics, users feel that their privacy has been violated. In addition, although the Internet search index improves the accuracy of predicting users' preferences and behavior [78], the recommender system used in the application may also disclose users' privacy [79]. In this case, due to social norms and impression management concerns, users may feel that their behavior cannot be entirely determined by themselves and finally think that the platform cannot meet their needs for autonomy. This view is further confirmed by the comparative study between Facebook and Twitter. Facebook's real name policy makes many users feel limited in expressing 
TABLE 8: Regression results.

\begin{tabular}{|c|c|c|c|c|c|c|c|c|}
\hline & SP & CS & RF & BOC & MV & $\mathrm{COM}$ & $\mathrm{SO}$ & KA \\
\hline \multicolumn{9}{|c|}{ Psychological needs } \\
\hline A & $0.027(0.089)$ & $0.053(0.097)$ & $-0.018(0.088)$ & $\begin{array}{c}0.309^{* * *} \\
(0.079)\end{array}$ & & & $-0.008(0.079)$ & \\
\hline $\mathrm{R}$ & $\begin{array}{c}0.223^{* *} \\
(0.106)\end{array}$ & & $\begin{array}{c}0.245^{* *} \\
(0.097)\end{array}$ & $-0.075(0.084)$ & $\begin{array}{c}0.227^{* *} \\
(0.079)\end{array}$ & $0.051(0.130)$ & & \\
\hline $\mathrm{C}$ & & & & & $\begin{array}{c}0.270^{* * *} \\
(0.078)\end{array}$ & & $\begin{array}{c}0.366^{* * *} \\
(0.084)\end{array}$ & $\begin{array}{c}0.369^{* * *} \\
(0.055)\end{array}$ \\
\hline $\mathrm{HP}$ & $\begin{array}{c}0.300^{* * *} \\
(0.092)\end{array}$ & $\begin{array}{c}0.260^{* * *} \\
(0.101)\end{array}$ & & & & & & \\
\hline CK & & & & $\begin{array}{l}0.246^{* *} \\
(0.078)\end{array}$ & $\begin{array}{l}0.189^{* *} \\
(0.066)\end{array}$ & & & \\
\hline ES & $\begin{array}{l}0.219^{* *} \\
(0.084)\end{array}$ & $0.179^{*}(0.088)$ & $\begin{array}{c}0.340^{* * *} \\
(0.085)\end{array}$ & & $0.167^{*}(0.067)$ & $0.114(0.116)$ & & \\
\hline $\mathrm{MC}$ & $0.013(0.088)$ & $0.092(0.087)$ & & & & & & \\
\hline Gender & \multicolumn{7}{|c|}{ Controls } & $0.052(0.077)$ \\
\hline Age & $0.047(0.089)$ & $-0.035(0.097)$ & $0.142^{*}(0.090)$ & $-0.004(0.080)$ & $-0.044(0.069)$ & $\begin{array}{l}-0.085 \\
(0.122)\end{array}$ & $-0.126(0.080)$ & $-0.056(0.055)$ \\
\hline IE & $-0.102(0.122)$ & $-0.046(0.132)$ & $0.019(0.125)$ & $0.065(0.110)$ & $-0.101(0.093)$ & $\begin{array}{l}-0.075 \\
(0.169)\end{array}$ & $0.092(0.108)$ & $-0.117(0.073)$ \\
\hline$R^{2}$ & 0.321 & 0.180 & 0.274 & 0.193 & 0.417 & 0.043 & 0.170 & 0.161 \\
\hline $\operatorname{Adj} R^{2}$ & 0.294 & 0.151 & 0.252 & 0.169 & 0.397 & 0.019 & 0.149 & 0144 \\
\hline
\end{tabular}

Note: ${ }^{*} p<0.05,{ }^{* *} p<0.01,{ }^{* * *} p<0.001$, standardized coefficients (standard errors); IE=Internet experience; Gender: $1=$ male, $2=$ female; SP = self-presentation; $\mathrm{CS}=$ content sharing; $\mathrm{RF}=$ relationship formation; $\mathrm{BOC}=$ browsing others' content; $\mathrm{MV}=\mathrm{meta}-\mathrm{voicing}$; $\mathrm{COM}=\mathrm{communication}$; $\mathrm{SO}=$ sourcing; $\mathrm{KA}=$ knowledge attributes.

themselves, while Twitter's anonymity system reduces users' social pressure and enables people to express themselves more freely [10, 80, 81].

The need for relatedness can motivate the use of Zhihu that has affordances of self-presentation, relationship formation, and meta-voicing, but there is no significant link from relatedness to browsing others' content and communication. Although browsing others' content and communication are also likely to help users develop their relationships with others, our results show that these affordances are not able to meet the psychological needs of relatedness. This may be because when users are provided with various affordances that can meet the same psychological needs, they will choose the one that can directly meet their psychological needs. In addition, compared to social platforms such as Wechat, OKC platforms such as Zhihu have weaker functions in chatting, which may also be why people are less likely to use chatting on Zhihu to meet needs for relatedness. According to results, the features which enable affordances of self-presentation, relationship formation, and meta-voicing are used to meet needs for relatedness on Zhihu.

The need for competence is significantly related to affordances of meta-voicing, sourcing, and knowledge attributes. As a successful OKC platform, the functions provided by Zhihu, such as commenting on posts, collecting and liking, voting for posts, suggesting questions, and searching answers, as well as the high-quality content of Zhihu, meet people's demands for applying and expanding their knowledge. The emergence of OKC platforms has changed the way people obtain information. Every online interaction or behavior of searching is the process of ingesting content through the Internet. This method has brought many positive effects, such as a variety of content and quick access to information, but there will also be some negative effects, for example, how to filter meaningful information which indeed enables users to acquire competence. In order to achieve substantial development, Zhihu should avoid information redundancy and maintain highquality content to win everyone's favor in the era of information overload.

The result supports the link between the need for having a place and the use of self-presentation and content sharing affordances. This shows that people create their own space by posting self-related content, writing the column, or sharing others' posts. Zhihu heavy users may invest a lot of time or money in engaging in Zhihu activities. In this way, people are able to be immersed in the environment they personalize for their own. As a result, the need for having a place can motivate the use of Zhihu that has affordances of selfpresentation and content sharing.

The need for coming to know the self can also drive people to use Zhihu that has affordances of browsing others' content and meta-voicing. People can establish self-identity by receiving feedback from others and comparing themselves with other people [72,73]. On the one hand, Zhihu can establish an effective feedback mechanism through such functions as liking and commenting so that users can constantly improve their answers, obtain new ideas, and may find the direction they are interested in and explore their potential. On the other hand, users will compare with their own articles or ideas by browsing other people's articles or opinions. Thus, they can find their own shortcomings and enhance their self-awareness. For example, by communicating with other users in the 
comment area, users may continue to be inspired and feel the differences between themselves and others to form a clearer understanding of themselves.

The result shows that individuals who have a great need to express self-identity may use Zhihu that provides affordances of self-presentation, content sharing, relationship formation, and meta-voicing. However, the affordance of communication could not fulfill people's psychological need for expressing self-identity. By joining an online community or following others (enable the affordance of relationship formation) on Zhihu, individuals are easy to express self-identity by establishing connections with other people. However, when users are high on the need for communicating their identities, the function of chatting may not be as rich as uploading their content, sharing others' content, commenting, or voting for others' posts (enable the self-presentation, content sharing, and meta-voicing affordances). In addition, as we mentioned before, compared to Wechat in China, the chatting function of Zhihu is not its superior function. Therefore, individuals are more likely to use self-presentation, content sharing, relationship formation, and meta-voicing to express selfidentity.

Finally, the need for maintaining continuity of selfidentity plays a nonsignificant role in driving Zhihu use.

We expect that the realization of this psychological need may only be a by-product of using Zhihu. Individuals could express their identity by posting their own content or sharing others' content. These constitute the user's previous and current experiences and records. Unless this material is specifically deleted, the information will be persistent, which provides continuity in time and a retrospective perspective for self-identity.

\section{Implications and Future Research}

7.1. Theoretical Implications. The characteristics of a particular OKC application provide insights into the affordances provided by that application. In addition, from the logic of NAF, this paper provides the mapping of the psychological needs that motivate using the application to its affordances. Therefore, people can predict their psychological needs based on the features provided by the OKC application. On the contrary, based on the people's level of psychological needs, it is possible to predict which affordances of the OKC application they may use.

Taking Zhihu as an example, this paper determines the psychological needs that drive the use of Zhihu from the perspective of the NAF model. Through the features of Zhihu, Zhihu affordances are identified, so the connection between affordances and psychological needs is established. Through the data collection and analysis, the results show that the salient psychological needs that motivate users to use Zhihu are autonomy, relatedness, competence, having a place, coming to know the self, and expressing self-identity, and these psychological needs are fulfilled by the affordances of browsing others' content (for autonomy), self-presentation, relationship formation and meta-voicing (for relatedness), meta-voicing, sourcing and knowledge attributes (for competence), self-presentation and content sharing (for having a place), browsing others' content and meta-voicing (for coming to know the self), and self-presentation, content sharing, relationship formation, and meta-voicing (for expressing self-identity). These results demonstrate how to use the NAF model to determine the relationship between a specific OKC platform and psychological needs.

\subsection{Practical Implications. From the fact that Wukong Q\&A} has invested billions in the construction of the community although it still fell to the ground, different platform affordances could create different community ecology. The research of this topic can guide more platforms to design more effective OKC applications under the premise of unifying user needs and organizational characteristics, which could lead to avoiding waste of social resources and improving the success rate of Internet innovation. Outwardly, the digital platform system has a certain degree of imitability and reproducibility. In fact, it contains differences in corporate value pursuit, user community, and core capabilities. The platform system is a collection of affordances generated during the interaction between the organizational characteristics of the platform enterprise and the needs of users. The platform must clearly understand the dominance and decisive role of these organizational characteristics in operations. Different organizational characteristics naturally require different digital technologies and combination options to achieve differentiated functions, interfaces, and processes and produce different user interaction effects. In addition to the social affordances provided by the platform, content platforms such as Zhihu should also focus on the affordances of knowledge content, that is, whether the content resources meet the platform positioning and user needs. Furthermore, platform strategies should be used to guide content production behavior and user consumption behavior to build a good user-content collaborative ecosystem.

7.3. Future Research. NAF model can be extended to design science research. For example, our results can be used to provide guidance on how to develop effective OKC application features. These features should be able to meet the natural psychological needs of users. In addition, although we have studied how each type of affordance meets specific psychological needs, it is also possible that affordances have joint complementary effects. Therefore, future research can explore whether a specific combination of affordances can provide better means to meet the psychological needs or whether a specific combination of characteristics can provide specific affordances in a better way. Third, it is unclear whether OKC applications should strive to provide multiple functions to meet a single demand or provide multiple functions to meet multiple needs in order to succeed. Our empirical research in the context of Zhihu shows that although Zhihu provides a variety of affordances to meet the needs for relatedness, only three of them may be significantly related to the need for relatedness. Although other affordances may also help individuals develop relationships with 
others, our results seem to indicate that this is not why users use them. This may be because when individuals are provided with multiple affordances that can meet the same psychological needs, they will choose the affordance that most directly meets the psychological needs. This is worthy of further study. Finally, we mentioned earlier that compared to other Q\&A platforms, Zhihu has carried out indepth content production and provided online and offline knowledge products. Whether users meet their psychological needs online or offline may depend on whether OKC provides better functions to meet their needs than offline. These questions are interesting directions for future design scientific research and provide potential ways for future $\mathrm{OKC}$ research to reveal how to attract users effectively.

\section{Data Availability}

The data are available from the corresponding author upon request.

\section{Conflicts of Interest}

The authors declare no conflicts of interest related to this article.

\section{References}

[1] I. Matar, "The integration of knowledge management into the Lebanese graphic design business sector," Journal of System and Management Sciences, vol. 8, no. 1, pp. 61-82, 2018.

[2] Z. K. Lin, F. J. Liu, and N. Zhao, "Research review on intrinsic mechanism of group collaboration in online knowledge community," Information Science, vol. 37, no. 6, 2019.

[3] J. N. Qiu, Y. Zhang, and K. Xu, "Research on the co-evolution of knowledge and social system based on individual heterogeneity in OKC," Operations Research and Management Science, vol. 27, no. 5, pp. 119-129, 2018.

[4] S. X. Zeng, The Research On Wukong Q\&A Content Operation, Hebei Technology University, Tianjin, China, 2016.

[5] L. H. Huang and Q. H. Zhu, "An analysis of wiki entry features and user contribution behavior: the case of baidu baike," Journal of Library Science in China, vol. 39, no. 203, pp. 79-88, 2013.

[6] A. Halfaker, R. S. Geiger, J. T. Morgan, and J. Riedl, “The rise and decline of an open collaboration system: how Wikipedia's reaction to popularity is causing its decline," American Behavioral Scientist, vol. 57, no. 5, pp. 664-688, 2013.

[7] R. E. Rice, S. K. Evans, K. E. Pearce, and A. Sivunen, "Organizational media affordances: perationalization and associations with media use," Journal of Communication, vol. 67, no. 1, pp. 106-130, 2017.

[8] A. Ghazawneh and O. A. Henfridsson, "Paradigmatic analysis of digital application market places," Journal of Information Technology, vol. 30, no. 3, pp. 198-208, 2015.

[9] R. W. Ongus and C. M. Nyamboga, "Collecting development practices in using information technology: a comparative study," Journal of Logistics, Informatics and Service Science, vol. 6, no. 2, pp. 1-22, 2019.

[10] E. Karahanna, S. X. Xu, Y. Xu, and N. Zhang, "The needsaffordances-features perspective for the use of social media," MIS Quarterly, vol. 42, no. 3, pp. 737-756, 2018.
[11] G. G. Parker and M. W. V. Alstyne, "Two-sided network effects: a theory of information product design," Management Science, vol. 51, pp. 1494-1504, 2005.

[12] Q. Zhong, X. F. Yang, and Z. Q. Wu, "A review of value cocreation in platform ecosystems," System Engineering-Theory and Practice, vol. 11, pp. 1-16, 2020.

[13] S. Luo, T. Yoshita, and Y. Wang, "Online knowledge community: conceptual clarification and a CAS view for its collective intelligence," Knowledge Science Engineeering and Management, Springer, Berlin, Germany, 2013.

[14] Y. Lu, C. Xiang, and B. Wang, "What affects information systems development team performance? An exploratory study from the perspective of combined socio-technical theory and coordination theory," Computers in Human Behavior, vol. 27, no. 2, pp. 811-822, 2011.

[15] U. Cress, I. Feinkohl, and J. Jirschitzka, "Mass collaboration as coevolution of cognitive and social systems," Mass Collaboration and Education, Springer International Publishing, New York, NY, USA, pp. 85-104, 2016.

[16] M. Alavi, D. E. Leidner, and W. Q. Zheng, "Knowledge management and knowledge management system: the conceptual foundation and research topic," MIS Quarterly, vol. 25, pp. 107-136, 2001.

[17] A. Beldad, M. D. Jong, and M. Steehouder, "How shall I trust the faceless and the intangible? A literature review on the antecedents of online trust," Computers in Human Behavior, vol. 26, no. 5, pp. 857-869, 2010.

[18] T. Guan, L. Wang, J. Jin, and X. Song, "Knowledge contribution behavior in online Q\&A communities: an empirical investigation," Computers in Human Behavior, vol. 81, pp. 137-147, 2018.

[19] H. M. Lai, C. P. Chen, and Y. F. Chang, "Determinants of knowledge seeking in professional virtual communities," Behaviour and Information Technology, vol. 33, no. 5, pp. 522-535, 2014.

[20] X. Zhao and S. M. Huang, "A comparative analysis between the antecedents of PVC knowledge seeking and antecedents of PVC knowledge contribution," Journal of Intelligence, vol. 36, no. 12, pp. 180-185, 2017, 137.

[21] S. Faraj, S. Kudaravalli, and M. M. Wasko, "Leading collaboration in online communities," MIS Quarterly, vol. 39, no. 2, pp. 393-412, 2015.

[22] J. J. Gibson, The Ecological Approach to Visual Perception, pp. 227-235, Lawrence Erlbaum Associates, Florence, KY, USA, 1986.

[23] A. Majchrzak and S. Faraj, "The contradictory influence of social media affordances on online communal knowledge sharing," Journal of Computer-Mediated Communication, vol. 19, no. 1, pp. 38-55, 2013.

[24] A. L. Fayard and J. Weeks, "Affordances for practice," Information and Organization, vol. 24, no. 4, pp. 236-249, 2014.

[25] H. Postigo, "The socio-technical architecture of digital labor: converting play into YouTube money," New Media \& Society, vol. 18, no. 2, pp. 332-349, 2016.

[26] Y. Sun, S. J. He, R. A. Shang, and J. D. Fu, "Research on the mechanism of corporate social work platforms affecting employees' improvisation ability-based on the perspective of online social networks," Management World, vol. 35, no. 3, pp. 157-168, 2019.

[27] J. W. Treem and P. M. Leonardi, "Social media use in organizations: exploring the affordances of visibility, editability, persistence, and association," Communication Yearbook, vol. 36, pp. 143-189, 2012. 
[28] M. Zhang, Research on the Influence of Function Affordance on the Traffic Import from Social Media to E-Commerce, Harbin Institute of Technology, Harbin, China, 2020.

[29] J. Fox and B. McEwan, "Distinguishing technologies for social interaction: the perceived social affordances of communication channels scale," Communication Monographs, vol. 84, no. 3, pp. 298-318, 2017.

[30] X. Y. Dong, The Impact of IT Affordance and Social Ties on Social Commerce Purchase Intention, Harbin Institute Of Technology, Harbin, China, 2018.

[31] Z. D. Pan and Y. S. Liu, "What is "new"? The power trap in the discourse of "new media" and the researcher's theoretical introspection: an interview with Professor Pan Zhongdang," News and Communications Review, vol. 1, pp. 2-19, 2017.

[32] Z. A. Zhang and J. L. Huang, "Research and implications on the affordance of internet platforms from the perspective of communication studies," New Writing, vol. 10, pp. 87-95, 2020.

[33] E. L. Deci and R. M. Ryan, Intrinsic Motivation and SelfDetermination in Human Behavior, Plenum Group, London, UK, 1985.

[34] J. M. Hermans and E. Hermans-Jansen, Self-Narratives: The Construction of Meaning in Psychotherapy, The Guilford Press, New York, NY, USA, 1995.

[35] H. J. Hermans, "The dream in the process of valuation: a method of interpretation," Journal of Personality and Social Psychology, vol. 53, no. 1, pp. 163-175, 1987.

[36] E. L. Deci and R. M. Ryan, "The support of autonomy and the control of behavior," Journal of Personality and Social Psychology, vol. 53, no. 6, pp. 1024-1037, 1987.

[37] C. Burk, "The collecting instinct," Pedagogical Seminary, vol. 7, no. 2, pp. 179-207, 1900.

[38] H. Dittmar, The Social Psychology Of Material Possessions: To Have is to Be, Hemel Hempstead, Harvester Wheatsheaf, Hertfordshire, UK, 1992.

[39] J. D. Porteous, "Home: the territorial core," Geographical Review, vol. 66, no. 4, pp. 383-390, 1976.

[40] S. P. Shi, X. Y. He, J. Zhang, J. Hong, and Y. Wu, "Value realization of internet start-ups from the perspective of affordance: a case study based on zhong you bang," Management Case Studies Journal, vol. 13, no. 3, pp. 315-330, 2020.

[41] A. Davis, J. Murphy, D. Owens, D. Khazanchi, and I. Zigurs, "Avatars, people, and virtual worlds: foundations for research in metaverses," Journal of the Association for Information Systems, vol. 10, no. 2, pp. 91-117, 2009.

[42] D. Halpern and J. Gibbs, "Social media as a catalyst for online deliberation? Exploring the affordances of Facebook and YouTube for political expression," Computers in Human Behavior, vol. 29, no. 3, pp. 1159-1168, 2013.

[43] I. Junglas, L. Goel, C. Abraham, and B. Ives, "The social component of information systems-how sociability contributes to technology acceptance," Journal of the Association for Information Systems, vol. 14, no. 10, pp. 585-616, 2013.

[44] L. Nardon and K. Aten, "Valuing virtual worlds: the role of categorization in technology assessment," Journal of the Association for Information Systems, vol. 13, no. 10, pp. 772-796, 2012.

[45] J. H. Kietzmann, K. Hermkens, I. P. McCarthy, and B. S. Silvestre, "Social media? Get serious! Understanding the functional building blocks of social media," Business Horizons, vol. 54, no. 3, pp. 241-251, 2011.

[46] M. Mesgari and F. Faraj, "Technology affordances: the case of Wikipedia," in Proceedings of the 18th Americas Conference on Information Systems, Seattle, WA, USA, 2012.
[47] L. Goel, N. Johnson, I. Junglas, and B. Ives, "Predicting users' return to virtual worlds: a social perspective," Information Systems Journal, vol. 23, no. 1, pp. 35-63, 2013.

[48] S. Faraj, S. L. Jarvenpaa, and A. Majchrzak, "Knowledge collaboration in online communities," Organization Science, vol. 22, no. 5, pp. 1224-1239, 2011.

[49] Z. M. Zhu, B. Delphine, and G. Iryna, "A multi-dimensional model for assessing the quality of answers in social Q\&A sites," in Proceedings of the 14th International Conference on Information Quality, Potsdam, Germany, November 2009.

[50] S. Kim and S. Oh, "Users' relevance criteria for evaluating answers in asocial Q\&A site," Journal of the American Society for Information Science and Technology, vol. 60, no. 4, pp. 716-727, 2009.

[51] J. Gibbs, N. Rozaidi, and J. Eisenberg, "Overcoming the "ideology of openness": probing the affordances of social media for organizational knowledge sharing," Journal of Computer-Mediated Communication, vol. 19, no. 1, pp. 102120, 2013.

[52] S. Cai, H. R. Shi, X. Fu, and X. Chen, "Research on the factors influencing the sales of paid knowledge products: taking Zhihu live as an example," Journal of Management in Engineering, vol. 33, no. 3, pp. 71-83, 2019.

[53] H. S. Cai, "Examining economic law from the perspective of interests," Social Scientist, vol. 7, 2008.

[54] B. H. Zou and H. Luo, "Knowledge payment-a knowledge dissemination model centered on openness, sharing and payment," New Media Research, vol. 3, no. 11, pp. 110-112, 2017.

[55] K. T. Tian, W. Bearden, and G. L. Hunter, "Consumer need for uniqueness: scale development and validation," Journal of Consumer Research, vol. 28, no. 1, pp. 50-67, 2001.

[56] C. Shah and J. Pomerantz, "Evaluating and predicting answer quality in community QA," in Proceedings of the 33rd International ACM SIGIR Conference on Research and Development in Information Retrieval, Geneva, Switzerland, July 2010.

[57] Y. Q. Hou and M. Xiao, "The development of socialized question-and-answer community and its communication characteristics: taking Zhihu as an example," Northern Media Research, vol. 4, pp. 37-41, 2017.

[58] Zhihu.Com, 2021, https://www.zhihu.com.

[59] N. N. Yin, "Research on the development of Zhihu APP knowledge service-based on SWOT-AHP analysis," Today's Massmedia, vol. 29, no. 3, pp. 34-36, 2021.

[60] iResearch, China Knowledge Marketing White Paper--Taking Zhihu as an example in 2018, iResearch Publications, Shanghai, China, 2018.

[61] E. L. Deci, Why We Do What We Do: Understanding Self Motivation, Penguin Books, New York, NY, USA, 1995.

[62] E. L. Deci and R. M. Ryan, Handbook of Self-Determination Research, University of Rochester Press, Rochester, NY, USA, 2002.

[63] E. L. Deci and R. M. Ryan, "The 'what' and 'why' of goal pursuits: human needs and the self-determination of behavior," Psychological Inquiry, vol. 11, no. 4, pp. 227-268, 2000.

[64] M. A. Jenkins-Guarnieri, S. L. Wright, and L. M. Hudiburgh, "The relationships among attachment style, personality traits, interpersonal competency, and Facebook use," Journal of Applied Developmental Psychology, vol. 33, no. 6, pp. 294-301, 2012.

[65] J. P. Seder and S. Oishi, "Ethnic/racial homogeneity in college students' Facebook friendship networks and subjective well- 
being," Journal of Research in Personality, vol. 43, pp. 438443, 2009.

[66] J. J. Bauer and D. P. McAdams, "Competence, relatedness, and autonomy in life stories," Psychological Inquiry, vol. 11, no. 4, pp. 276-279, 2000.

[67] R. W. White, "Motivation reconsidered: the concept of competence," Psychological Review, vol. 66, no. 5, pp. 297-333, 1959.

[68] H. Barki, G. Paré, and C. Sicotte, "Linking IT implementation and acceptance via the construct of psychological ownership of information technology," Journal of Information Technology, vol. 23, no. 4, pp. 269-280, 2008.

[69] T. M. Harrison and B. Barthel, "Wielding new media in web 2.0: exploring the history of engagement with the collaborative construction of media products," New Media \& Society, vol. 11, no. 1/2, pp. 155-178, 2009.

[70] J. L. Pierce, T. Kostova, and K. T. Dirks, “Toward a theory of psychological ownership in organizations," Academy of Management Review, vol. 26, no. 2, pp. 298-310, 2001.

[71] J. L. Pierce, T. Kostova, and K. T. Dirks, "The state of psychological ownership: integrating and extending a century of research," Review of General Psychology, vol. 7, no. 1, pp. 84-107, 2003.

[72] L. Festinger, "A theory of social comparison processes," Human Relations, vol. 7, no. 2, pp. 117-140, 1954.

[73] G. H. Mead, Mind, Self and Society, University of Chicago Press, Chicago, IL, USA, 1934.

[74] E. L. Deci and R. M. Ryan, "A motivational approach to self: integration in personality," in Proceedings of the Nebraska Symposium on Motivation, vol. 38, pp. 237-288, University of Nebraska Press, Lincoln, NE, USA, 1991.

[75] R. F. Devellis, Scale Development Theory and Applications, Sage, London, UK, 1991.

[76] J. F. Hair, W. C. Black, B. J. Babin, and R. E. Anderson, Multivariate Date Analysis: A Global Perspective, PrenticeHall, Upper Sadder River, NJ, USA, 2010.

[77] C. Fornell and D. F. Larcker, "Evaluating structural equation models with unobservable variables and measurement error," Journal of Marketing Research, vol. 18, no. 1, pp. 39-50, 1981.

[78] Y. Li, M. Xu, X. Wen, and D. Guo, "The role of internet search index for tourist volume prediction based on GDFM model," Tehnicki vjesnik-Technical Gazette, vol. 27, no. 2, pp. 576-582, 2020.

[79] D. A. Sitar-Tăut, D. Mican, and C. Mare, "Customer behavior in the prior purchase stage-information search versus recommender systems," Economic Computation and Economic Cybernetics Studies and Research, vol. 54, no. 3, pp. 59-76, 2020.

[80] B. A. Huberman, D. M. Romero, and F. Wu, Social Networks that Matter: Twitter under the Microscope, Cornell University, Ithaca, NY, USA, 2008, http://ssrn.com/abstract=1313405 or http://dx.doi.org/10.2139/ssrn.1313405.

[81] D. J. Hughes, M. Rowe, M. Batey, and A. Lee, "A tale of two sites: twitter vs. Facebook and the personality predictors of social media usage," Computers in Human Behavior, vol. 28, no. 2, pp. 561-569, 2012. 